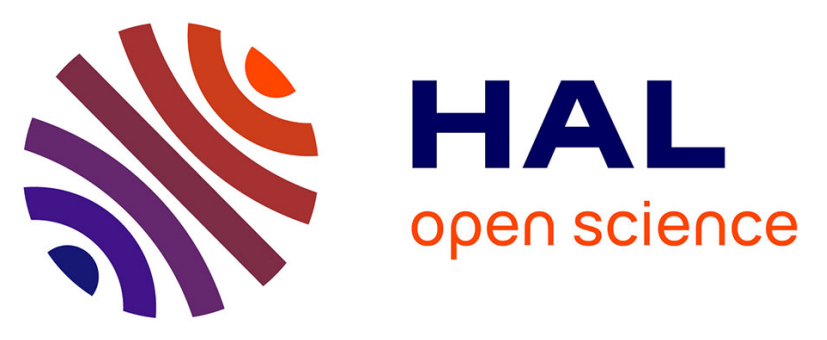

\title{
IMMUNO-METABOLIC SIGNATURES OF DENDRITIC CELLS ASSOCIATE WITH T-CELL RESPONSES IN MELANOMA PATIENTS
}

Juraj Adamik, Deena Maurer, Paul Munson, Alexis Combes, Philippe Pierre, Matthew Krummel, Rafael J Argüello, Lisa Butterfield

\section{To cite this version:}

Juraj Adamik, Deena Maurer, Paul Munson, Alexis Combes, Philippe Pierre, et al.. IMMUNOMETABOLIC SIGNATURES OF DENDRITIC CELLS ASSOCIATE WITH T-CELL RESPONSES IN MELANOMA PATIENTS. SICT, Nov 2020, Los Angeles, United States. pp.A325 - A325, 10.1136/jitc-2020-sitc2020.0299 . hal-03451694

\author{
HAL Id: hal-03451694 \\ https://hal.science/hal-03451694
}

Submitted on 26 Nov 2021

HAL is a multi-disciplinary open access archive for the deposit and dissemination of scientific research documents, whether they are published or not. The documents may come from teaching and research institutions in France or abroad, or from public or private research centers.
L'archive ouverte pluridisciplinaire HAL, est destinée au dépôt et à la diffusion de documents scientifiques de niveau recherche, publiés ou non, émanant des établissements d'enseignement et de recherche français ou étrangers, des laboratoires publics ou privés.

\section{(ㄷ)(i)}

Distributed under a Creative Commons Attribution| 4.0 International License 
Trial Registration Clinicaltrials. gov NCT01343043

Ethics Approval This study was approved by the appropriate institutional review boards and independent ethics committees.

http://dx.doi.org/10.1136/jitc-2020-SITC2020.0298

\section{IMMUNO-METABOLIC SIGNATURES OF DENDRITIC CELLS ASSOCIATE WITH T-CELL RESPONSES IN MELANOMA PATIENTS}

\begin{abstract}
${ }^{1} J u r a j$ Adamik*, ${ }^{2}$ Deena Maurer, ${ }^{1}$ Paul Munson, ${ }^{3}$ Alexis Combes, ${ }^{4}$ Philippe Pierre, ${ }^{3}$ Matthew Krummel, ${ }^{4}$ Rafael Argüello, 'Lisa Butterfield. 'Parker Institute for Cancer Immunotheray, University of California, San Francisco, San Francisco, CA, USA; ${ }^{2}$ University of Pittsburgh, Pittsburgh, PA, USA; ${ }^{3}$ University of California, San Francisco, San Francisco, CA, USA; ${ }^{4}$ Centre d'Immunologie de Marseille-Luminy, Marseille, France
\end{abstract}

Background The therapeutic efficacy of Dendritic cells (DC) vaccines remains low and there is an unmet need for more effective vaccine design to achieve durable clinical outcomes. Our study analyzed the transcriptomic and energetic metabolism profile of an adenoviral-based DC vaccine targeted against three commonly shared melanoma antigens: Tyrosinase, MART-1 and MAGE-A6 from 35 subjects enrolled in a Phase I study of autologous DC vaccines in late-stage melanoma. ${ }^{1}$ To further investigate the immuno-metabolic features of monocyte-derived DC vaccines, we are employing a novel flow cytometry-based method, called SCENITH ${ }^{2}$ to integrate functional metabolic states with multiparametric DC immune phenotypes.

Methods iDC were generated from $\mathrm{HD}$ and patient monocytes using GM-CSF+IL-4 for 5d. DC were matured (mDC) using IFN?+LPS for additional 24 hrs. Tolerogenic DC (Tol DC) were generated using vitamin-D3 and dexamethasone. Seahorse ${ }^{\circledR}$ was used to measure DC metabolic profile. Cytek/ Aurora spectral flow cytometry was used for multiparametricphenotypic and metabolic analysis by SCENITH ${ }^{\mathrm{TM}}$.

Results Melanoma patient mDC used for autologous vaccine generation showed significantly altered metabolic gene signatures associated with enhanced oxidative phosphorylation (OXPHOS) and lipid metabolism pathways as compared to HD mDC. Furthermore, increased enrichment for mitochondrial respiration genes involved in the TCA cycle, electron transport chain and fatty acid oxidation (FAO) correlated with inferior tumor antigen-specific $\mathrm{T}$ cell responses and clinical outcome in patients. Seahorse analyses confirmed that HD and good outcome patient DC demonstrated the highest maturation-induced reduction in maximal oxygen consumption rate/ OXPHOS and exogenous FAO. Interestingly, while the glycolytic rate of non-responding patient DC was the lowest, overall, we observe only a moderate increase in glycolytic capacity during DC maturation. SCENITH analysis showed that unlike monocytes, which are primarily glycolytic, differentiated mono-derived iDC and mDC utilize both glycolysis and mitochondrial respiration. Interestingly, under tolerogenic (Tol) differentiation conditions Tol iDC shift from glucose dependence into $\mathrm{FAO}$ and/or glutaminolysis while Tol $\mathrm{mDC}$ strongly depend on OXPHOS. Consistent with dependence on mitochondrial respiration, Tol mDC exhibit reduced HIF1a levels together with enhanced p-AMPK:p-mTOR ratio. Additionally, we show that the altered metabolism of Tol $\mathrm{mDC}$ is linked to retention of CD14-monocyte antigen with reduced DC markers HLA-DR, CD86, CD206, CD11c, CD33, with increased PD-L1 and ILT3 expression. Furthermore, we show that unlike $\mathrm{HD} \mathrm{mDC}$, tolerogenic and melanoma patient- derived mDC populations exhibit similar metabolic and immune characteristics.

Conclusions We demonstrate that metabolic profile of DCs is tightly associated to the immuno-stimulatory potential of DC vaccines from cancer patients. Using SCENITH, we linked phenotypic and functional metabolic changes associated to immune signatures that correspond to heathy and immunosuppressed DC differentiation.

Ethics Approval The clinical trial reported was fully approved by the Univ. Pittsburgh PRC and IRB (PRO12010416, \#09021) and had FDA IND \#15044 and NCT01622933.

\section{REFERENCES}

1. Butterfield LH, Vujanovic L, Santos PM, Maurer DM, Gambotto A, Lohr J, Li C Waldman J, Chandran U, Lin Y, et al. Multiple antigen-engineered DC vaccines with or without IFNalpha to promote antitumor immunity in melanoma. Journal for immunotherapy of cancer 2019;7:113.

2.. Argüello RJ, Combes AJ, Char R, Bousiquot E, Gigan JP, Camosseto V, Samad B, Tsui J, Yan P, et al. SCENITH: A flow cytometry based method for functional profiling energy metabolism with single cell resolution. BioRxiv 2020.03.10.985796; doi: https://doi.org/10.1101/2020.03.10.985796. Cell Metabolism. (Sneak and Peek: under review 10.2139/ssrn.3565001)

http://dx.doi.org/10.1136/jitc-2020-SITC2020.0299

\section{FINAL ANALYSIS OF A PROSPECTIVE, RANDOMIZED, DOUBLE-BLIND, PLACEBO-CONTROLLED PHASE IIB TRIAL OF TUMOR LYSATE, PARTICLE-LOADED, DENDRITIC CELL VACCINE IN STAGE III/IV MELANOMA: 36-MONTH ANALYSIS}

${ }^{1}$ Lexy Adams*, ${ }^{1}$ Robert Chick, ${ }^{1}$ Guy Clifton, ${ }^{1}$ Timothy Vreeland, ${ }^{1}$ Patrick McCarthy, ${ }^{1}$ Anne O'Shea, ${ }^{1}$ Phil Kemp Bohan, ${ }^{1}$ Annelies Hickeron, ${ }^{1}$ John Myers, 'Jessica Cindass, ${ }^{1}$ Diane Hale, ${ }^{2}$ Mark Faries, ${ }^{3}$ John Hyngstrom, ${ }^{4}$ Adam Berger, ${ }^{5}$ James Jakub, ${ }^{6}$ Jeffrey Sussman, ${ }^{7}$ Montaser Shaheen, ${ }^{8}$ Thomas Wagner, ${ }^{9}$ George Peoples. ${ }^{1}$ Brooke Army Medical Center, San Antonio, TX, USA; ${ }^{2} J o h n$ Wayne Cancer Institute, Los Angeles, CA USA; ${ }^{3}$ University of Utah, Salt Lake City, UT, USA; ${ }^{4}$ Rutgers Cancer Institute of New Jersey, philadelphia, PA, USA; ${ }^{5}$ Mayo Clinic, Rochester, MN, USA; ${ }^{6}$ University of Cincinatti, Cincinnati, OH, USA; ${ }^{7}$ University of Arizona, Pheonix, AZ, USA; ${ }^{8}$ Orbis Health Solutions, Greenville, SC, USA; ${ }^{9}$ Cancer Vaccine Development Program, San Antonio, TX, USA

Background The tumor lysate, particle-loaded, dendritic cell (TLPLDC) vaccine is created ex vivo by loading autologous dendritic cells (DC) with yeast cell wall particles (YCWP) containing autologous tumor lysate, thus delivering tumor antigens to the DC cytoplasm via phagocytosis. TLPLDC then activates a robust $\mathrm{T}$ cell response against the unique antigens for each patient. The primary analysis of the prospective, randomized, multi-center, double-blind, placebo-controlled phase IIb trial in patients with resected stage III/IV melanoma showed TLPLDC improved 24-month disease-free survival (DFS) in the pertreatment (PT) analysis (patients completing the 6-month primary vaccine series). Here, we examine the secondary endpoint of 36-month DFS and overall survival (OS).

Methods Patients with resected stage III/IV melanoma were randomized 2:1 to TLPLDC vaccine or placebo (autologous DC loaded with empty YCWP). Treatments were given at 0 , 1, 2, 6, 12 and 18 months. The protocol was amended to include patients receiving concurrent checkpoint inhibitors (CPIs) to follow changes in standard of care. The co-primary endpoints were 24-month DFS by intention-to-treat (IT) analysis and per-treatment (PT) analysis, with secondary endpoints including 36-month DFS and OS by ITT and PT analysis, prespecified analysis by stage, and safety as measured by CTCAE v4.03. 